\title{
Design of Dual-Band Substrate-Integrated Waveguide E-Plane Directional Couplers
}

\author{
Vladimir A. Labay ${ }^{1}$ and Jens Bornemann ${ }^{2}$ \\ ${ }^{1}$ Department of Electrical and Computer Engineering, Gonzaga University, Spokane, WA 99258, USA \\ ${ }^{2}$ Department of Electrical and Computer Engineering, University of Victoria, Victoria, BC V8W 3P6, Canada \\ ${ }^{1}$ labay@gonzaga.edu
}

\begin{abstract}
Dual-band substrate-integrated waveguide (SIW) couplers for operation in the $20 / 30 \mathrm{GHz}$ bands are presented. Initial design guidelines follow substrate selection and aperture coupling theory as known from standard air-filled waveguide components. The results demonstrate that this design approach is sufficient for many applications. All-dielectric waveguide ports as well as microstrip ports are used as interfaces to the SIW couplers. Designs are analyzed within an Ansoft HFSS environment, and the approach is verified by comparison with results obtained from CST Microwave Studio. Performances of several prototype designs are presented for dual-band coupling values between $6 \mathrm{~dB}$ and $20 \mathrm{~dB}$. All coupler dimensions are specified.
\end{abstract}

Index Terms - Substrate-integrated waveguide, dual-band couplers, aperture couplers, E-plane couplers, aperture theory, SIW transitions.

\section{INTRODUCTION}

Frequency allocations for modern satellite and terrestrial communication systems demand that large parts of a feed system be capable of dual-band operation, e.g. [1], [2]. Since many of such systems require a band separation of 1.5 (e.g. $12 / 18 \mathrm{GHz}$ or $20 / 30 \mathrm{GHz}$ ) [3], the bandwidth provided by regular waveguides is often insufficient. Thus a dual-band feed-system component must either exhibit dual-plane symmetry to limit excitation of higher-order modes, e.g. [1], [4], [5], incorporate band-extending features such as ridges [6], or use a different technology altogether.

Due to cost and space restrictions, components in communication and millimeter-wave receivers are increasingly fabricated in substrate-integrated waveguide (SIW) technology which provides a reasonable compromise between microstrip and waveguide circuitry [7], [8] and has been proven to work satisfactorily up to the $100 \mathrm{GHz}$ frequency range [9], [10].

Therefore, this paper presents an initial design approach for dual-band E-plane couplers in SIW technology. Based on a previous investigation on broadband couplers [11], the design process for dual-band operation is explained and example performances presented and validated.

\section{DESIGN PROCESS}

Fig. 1 shows two dual-band SIW E-plane couplers with $N=4$ aperture pairs. The circuit in Fig. 1a uses all-dielectric waveguide ports which are used for faster computation and if the dual-band coupler is to be integrated with other SIW circuitry [11]. Fig. 1b shows a similar coupler with microstrip ports as typically employed if the dual-band coupler is used as a stand-alone component.

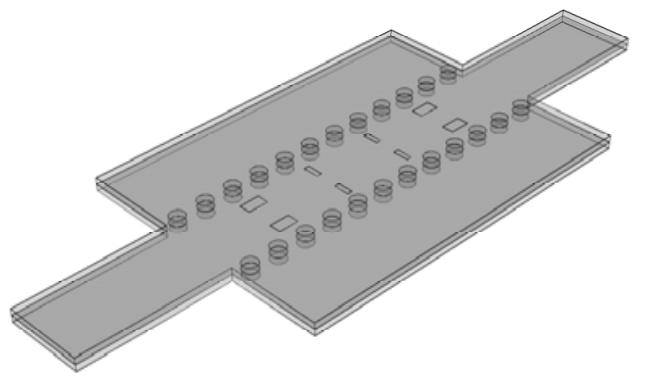

(a)



(b)

Fig. 1. Dual-band SIW E-plane directional couplers with microstrip ports (a) and all-dielectric waveguide ports (b).

\section{A. Substrate and Via Parameters}

One of the first decisions for the design of the SIW dualband coupler is the choice of the substrate material and/or the placement and dimensions of the via holes. Keep in mind that the dual-band operation for the coupler - due to its wide spacing of the frequency bands $(20 / 30 \mathrm{GHz})$ - is obtained through quarter-wavelength (lower band) and three quarterwavelengths (upper band) spacing. (Note that a different approach is presented in [6] for dual-band waveguide 
transformers, but is not adopted here as it frequently leads to unpractical (overlapping) apertures.) Thus the size and position of the vias must satisfy the wavelength ratio for the two bands.

The design parameters for the vias with respect to the equivalent waveguide width are obtained in close-form expressions from [7], [8].

For the $20 / 30 \mathrm{GHz}$ designs presented in this paper, the substrate was selected as RT Duroid with $\varepsilon_{\mathrm{r}}=2.2$, height $b=$ $0.508 \mathrm{~mm}$ and metallization thickness $t=35 \mu \mathrm{m}$. To approximately satisfy the guided wavelength ratio of the two bands, the equivalent waveguide width was set to $a_{\text {equ }}=$ $6.3664 \mathrm{~mm}$ which, using via diameters of $d=1.19 \mathrm{~mm}$, results in a waveguide width of $a=7.1 \mathrm{~mm}$ between the centers of the left and right rows of vias. The via center-tocenter spacing in propagation direction is $p=2.397 \mathrm{~mm}$ according to recommendations in [12]. A transition from such an SIW to microstrip, as depicted in Fig. 1a, follows from [7]. The width of the $50 \Omega$ microstrip line is $1.546 \mathrm{~mm}$, the width at the SIW junction is $2.401 \mathrm{~mm}$, and the length of the linear taper between these two widths is $6.5 \mathrm{~mm}$.

\section{B. Apertures}

Apertures are formed by removing the metallization from one of the two stacked SIWs. The aperture is air-filled with a thickness is $t=35 \mu \mathrm{m}$. The design process follows the equivalent-circuit dual-hole synthesis approach given in [13]. The center-to-center distance between apertures is set to one quarter of the electrical length at the lower band's midband frequency. Note that this parameter includes the influence of the adjacent coupling apertures [13]. Since only a single aperture parameter per dual-hole can be varied to satisfy the value dictated by the equivalent circuit, square apertures are assumed initially. Fine optimization within HFSS varies slightly the obtained aperture sizes and their spacing.

In a standard waveguide coupler, the distance between the waveguide center and the centers of the dual-slot apertures is approximately one quarter of the waveguide width. In order to provide slightly more separation between the apertures and the vias, this distance was slightly reduced to $0.232 a_{\text {equ }}$ or $1.477 \mathrm{~mm}$.

\section{RESULTS}

This section presents a number of dual-band couplers for the $20 / 30 \mathrm{GHz}$ range. In the following performance plots, ports 1, 2, 3 and 4 are, respectively, the input, through, coupled and isolated ports.

A direct comparison between results obtained by Ansoft HFSS and CST Microwave Studio is presented in Fig. 2 at the example of a $10 \mathrm{~dB}$ dual-band coupler with $N=8$ dual holes and all-dielectric waveguide ports. Good agreement is observed between the results of the two commercial software packages, thus verifying the design approach. Better than 25
$\mathrm{dB}$ isolation and return loss is achieved for the two bands at 17-20 GHz and 27-32 GHz.

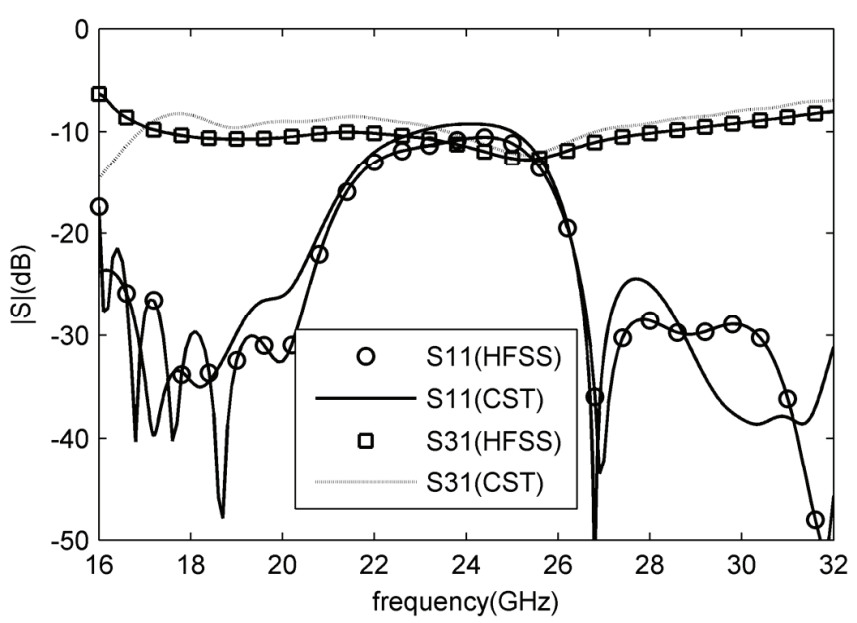

(a)

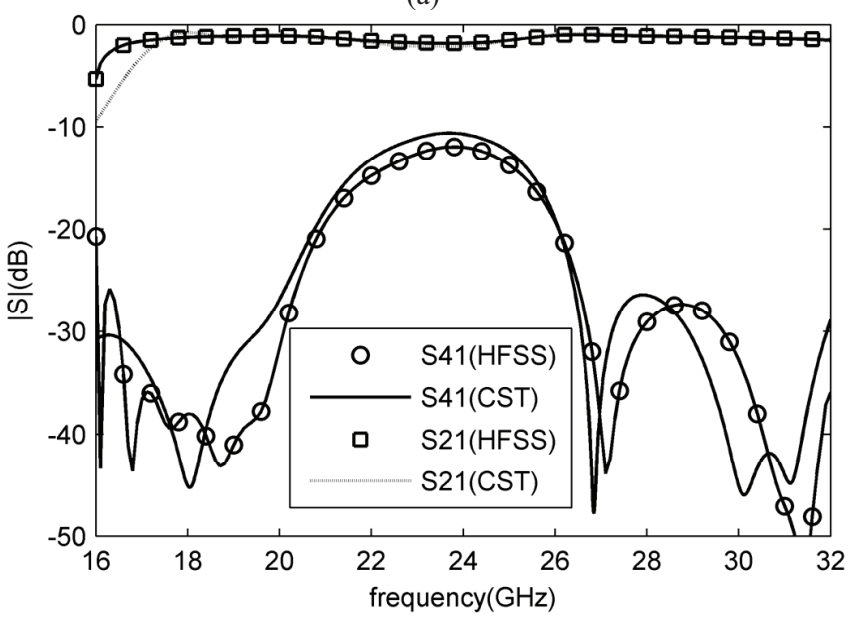

(b)

Fig. 2. Comparison between HFSS and CST at the example of a $10 \mathrm{~dB}$ dual-band coupler with $N=8$ dual holes and all-dielectric waveguide ports; (a) input return loss and coupling; (b) isolation and through port.

Fig. 3 shows a comparison between the two circuits shown in Fig. 1. They use only four aperture pairs and are designed for a coupling value of $15 \mathrm{~dB}$. Fig. 3a shows the circuit with all-dielectric waveguide ports. The coupling is fairly constant over the entire band, and the isolation is better than $20 \mathrm{~dB}$ above $18 \mathrm{GHz}$. The limiting factor for this design with $N=4$ is the return loss whose performance is better than $22.5 \mathrm{~dB}$ from $18 \mathrm{GHz}$ to $23 \mathrm{GHz}$ and above $26 \mathrm{GHz}$.

Fig. $3 \mathrm{~b}$ shows a similar circuit but with microstrip ports. Whereas such SIW-to-microstrip transitions usually work satisfactory in most of the frequency range supported by the SIW structure, they are frequently influencing the lower frequency band. This is evident in the $17 \mathrm{GHz}$ to $20 \mathrm{GHz}$ range in Fig. 3b where a performance similar to that in Fig. 3a could not be achieved. Note that the all-dielectric waveguide 
ports in Fig. 1a are much less reflective (as would be a different connected SIW circuit) than the microstrip ports in Fig. 1b.



(a)

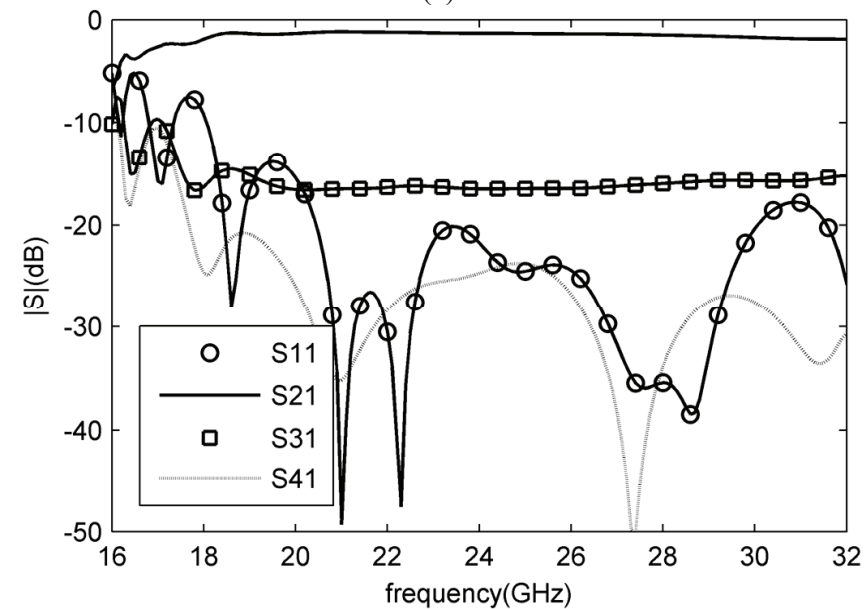

(b)

Fig. 3. Performances of $15 \mathrm{~dB}$ dual-band couplers with $N=4$ dual holes; (a) design with all-dielectric waveguide ports according to Fig. 1a and (b) with microstrip ports as shown in Fig. 1b.

The performance of a $20 \mathrm{~dB}$ dual-band coupler with eight dual apertures is shown in Fig. 4. The coupling value remains fairly constant over the entire frequency range between 17 $\mathrm{GHz}$ and $32 \mathrm{GHz}$. However, return loss and isolation have been designed to achieve dual-band operation and are better than $25 \mathrm{~dB}$ between $17 \mathrm{GHz}$ and $21.5 \mathrm{GHz}$ as well as between $29 \mathrm{GHz}$ and $32 \mathrm{GHz}$. Note that for such a low coupling value, the initial set of square apertures is sufficient, and fine optimization is not required.

Finally, a dual-band component with tighter coupling (6 $\mathrm{dB})$ is shown in Fig. 5. Such a design requires a higher number of coupling apertures, and Fig. 5a shows $N=14$ aperture pairs. Design specifications called for $24 \mathrm{~dB}$ return loss and isolation from $17 \mathrm{GHz}$ to $20 \mathrm{GHz}$ as well as from 27 $\mathrm{GHz}$ to $31 \mathrm{GHz}$. This was achieved in Fig. 5b by using the initial design procedure outlined in Section II and fine optimization. The coupling remains fairly constant over the two frequency bands.

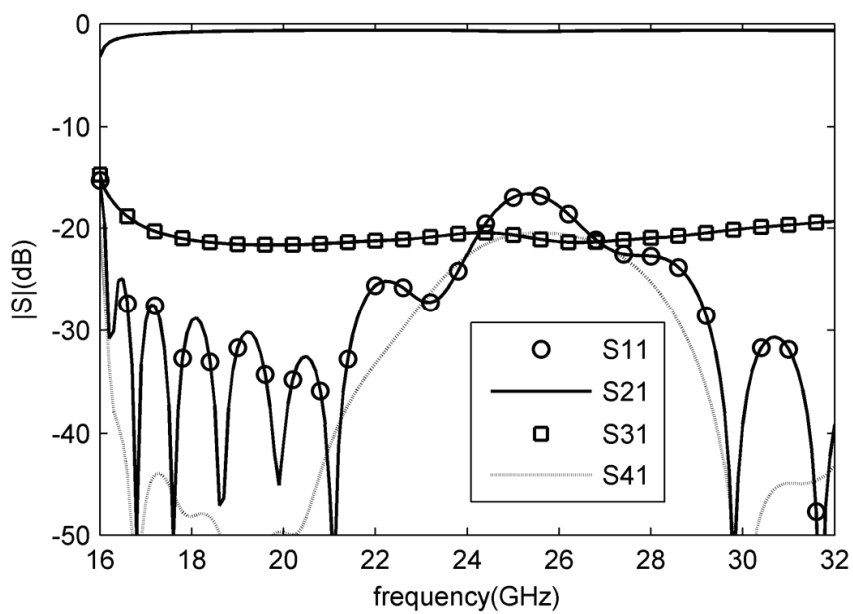

Fig. 4. Performance of $20 \mathrm{~dB}$ dual-band coupler with $N=8$ dual holes and all-dielectric waveguide ports.

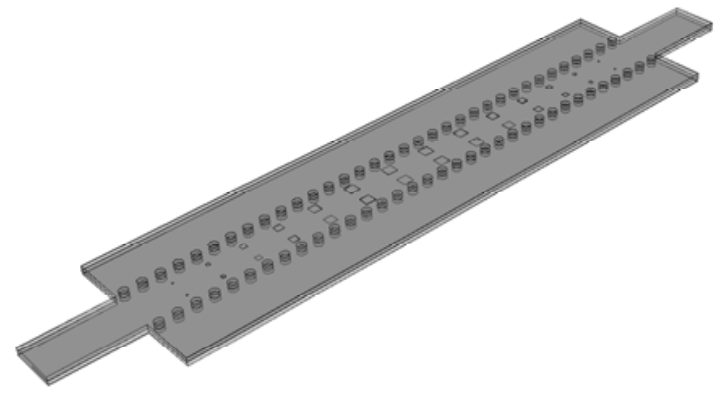

(a)

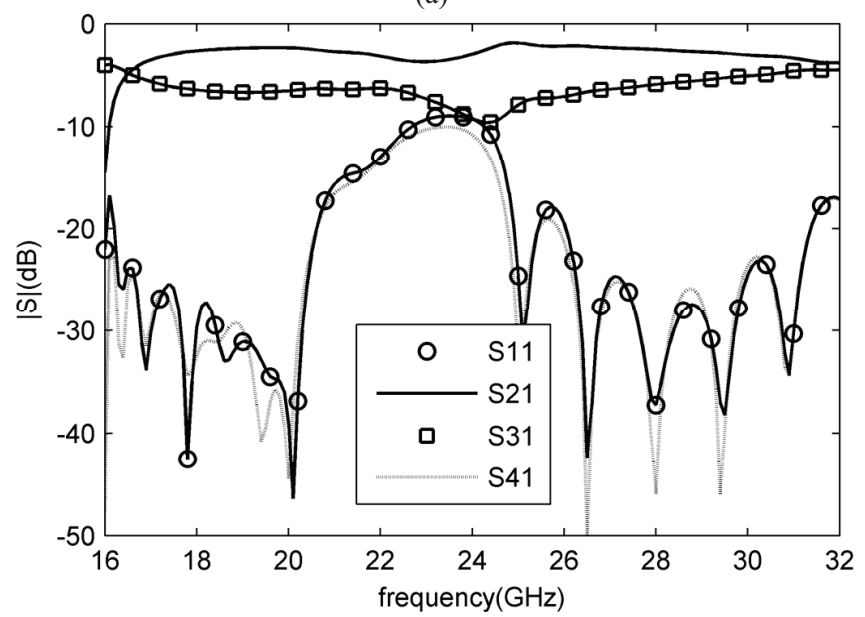

(b)

Fig. 5. $6 \mathrm{~dB}$ dual-band coupler with $N=14$ dual holes and alldielectric waveguide ports (a); performance (b).

In addition to the basic design parameters outlined in Section II, Table I presents the aperture dimensions of all couplers shown in this paper. Note that distances $d$ between apertures are measured center to center and that all dual-band 
TABLE I

DIMENSIONS IN MM

\begin{tabular}{|c|c|c|c|c|c|}
\hline $\begin{array}{c}\text { Number } N \text { of } \\
\text { Aperture } \\
\text { Pairs } \\
\end{array}$ & Coupling [dB] & $\begin{array}{c}\text { Longitudinal } \\
\text { Length of } \\
\text { Aperture } \\
\end{array}$ & $\begin{array}{c}\text { Transversal } \\
\text { Length of } \\
\text { Aperture } \\
\end{array}$ & $\begin{array}{c}\text { Distance } \\
\text { Between } \\
\text { Apertures } \\
\end{array}$ & Figure \\
\hline 8 & 10 & $\begin{array}{l}l_{1}=0.457 \\
l_{2}=0.859 \\
l_{3}=1.230 \\
l_{4}=1.452\end{array}$ & $\begin{array}{l}w_{1}=0.327 \\
w_{2}=0.738 \\
w_{3}=1.144 \\
w_{4}=1.476\end{array}$ & $\begin{array}{l}d_{1}=4.869 \\
d_{2}=5.190 \\
d_{3}=5.590 \\
d_{4}=5.776\end{array}$ & 2 \\
\hline 4 & 15 & $\begin{array}{l}l_{1}=1.598 \\
l_{2}=0.407\end{array}$ & $\begin{array}{l}w_{1}=0.939 \\
w_{2}=1.261\end{array}$ & $\begin{array}{l}d_{1}=5.416 \\
d_{2}=5.755\end{array}$ & 3 \\
\hline 8 & 20 & $\begin{array}{l}l_{1}=0.311 \\
l_{2}=0.578 \\
l_{3}=0.824 \\
l_{4}=0.968\end{array}$ & $\begin{array}{l}w_{1}=l_{1} \\
w_{2}=l_{2} \\
w_{3}=l_{3} \\
w_{4}=l_{4}\end{array}$ & $\begin{array}{l}d_{1}=4.774 \\
d_{2}=4.893 \\
d_{3}=5.048 \\
d_{4}=5.123\end{array}$ & 4 \\
\hline 14 & 6 & $\begin{array}{l}l_{1}=0.298 \\
l_{2}=0.546 \\
l_{3}=0.903 \\
l_{4}=0.910 \\
l_{5}=0.913 \\
l_{6}=1.382 \\
l_{7}=1.675\end{array}$ & $\begin{array}{l}w_{1}=0.242 \\
w_{2}=0.438 \\
w_{3}=1.021 \\
w_{4}=0.777 \\
w_{5}=1.119 \\
w_{6}=1.284 \\
w_{7}=1.508\end{array}$ & $\begin{aligned} d_{1} & =4.744 \\
d_{2} & =4.824 \\
d_{3} & =5.011 \\
d_{4} & =5.304 \\
d_{5} & =5.624 \\
d_{6} & =5.863 \\
d_{7} & =5.949\end{aligned}$ & 5 \\
\hline
\end{tabular}

couplers are symmetric such that $l_{1}=l_{N}, l_{2}=l_{N-2}$, etc., $w_{1}=$ $w_{N}, w_{2}=w_{N-1}$, etc., $d_{1}=d_{N}, d_{2}=d_{N-1}$, etc.

\section{CONCLUSIONS}

Guidelines for the design of dual-band SIW E-plane couplers are discussed. Example performances of components operating in the $20 / 30 \mathrm{GHz}$ bands demonstrate that the approach presents a viable option towards layered SIW circuit design. The use of all-dielectric waveguide ports facilitates computational speed and simulates integration of the coupler with other SIW circuitry. Microstrip ports somewhat degrade the coupler performance and are recommended only for measuring purposes or if the coupler is used as a stand-alone component. The HFSS-based design approach is shown to work well for coupling values between $6 \mathrm{~dB}$ and $20 \mathrm{~dB}$ and is verified by comparison with results obtained by CST Microwave Studio.

\section{REFERENCES}

[1] P. Chambelin, and J.F. Pintos, "Design and optimization of dual and wide band polarizer for low cost Ka band applications," 2006 IEEE AP-S Int. Symp. Dig., pp. 1595-1598, Albuquerque, USA, July 2006

[2] H.A. Thiart, K. Rambabu, and J. Bornemann, "Prototype design of a dual-band dual-polarization Ku/Ka-band feed," Proc. European Microwave Association, vol. 2, pp. 318-325, December 2006

[3] S. Rao, K.K.Chan, and M. Tang, "Dual-band multiple beam antenna system for satellite communications," 2005 IEEE AP-S Int. Symp. Dig., pp. 359 - 362, Washington, DC, USA, July 2005
[4] J.M. Rebollar, and J. Esteban, "CAD of corrugated circularrectangular waveguide polarizers," Proc. $8^{\text {th }}$ Int. Conf. Antennas Propagat. (ICAP), p. 845-848, Edinburgh, UK, March/April 1993.

[5] J. Bornemann, and M. Mokhtaari, "Initial design and optimization of broad-band and dual-band square-to-circular waveguide transitions", Proc. 2005 Asia-Pacific Microwave Conf., pp. 726-728, Suzhou, China, December 2005.

[6] U. Rosenberg, J. Bornemann, and S. Amari, "Design of dualband waveguide transformers", 2005 IEEE MTT-S Int. Microwave Symp. Dig., pp. 1215-1218, Long Beach, USA, June 2005.

[7] D. Deslandes, and K. Wu, "Integrated microstrip and rectangular waveguide in planar form", IEEE Microwave Wireless Comp. Lett., vol. 11, pp. 68-70, February 2001.

[8] Y. Cassivi, L. Perregrini, P. Arcioni, M. Bressan, K. Wu, and G. Conciauro, "Dispersion characteristics of substrate integrated rectangular waveguide", IEEE Microwave Wireless Comp. Lett., vol. 12, pp. 333-335, September 2002.

[9] E. Moldovan, R.G. Bosisio, and K. Wu, "W-band multiport substrate-integrated waveguide circuits", IEEE Trans. Microwave Theory \& Tech., vol. 54, pp. 625-632, February 2006.

[10] D. Stephens, P.R. Young, and I.D. Robertson, "Millimeterwave substrate integrated waveguides and filters in photoimageable thick-film technology," IEEE Trans. Microwave Theory \& Tech., vol. 53, pp. 3832-3838, December 2005.

[11] V.A. Labay, and J. Bornemann, "E-Plane directional couplers in substrate-integrated waveguide technology", in Proc. 2008 Asia-Pacific Microwave Conf., A1-75, 4 p., Hong Kong, December 2008.

[12] D. Delandes, and K. Wu, "Single-substrate integration technique of planar circuits and waveguide filters," IEEE Trans. Microwave Theory \& Tech., vol. 51, pp. 593-596, February 2003

[13] J. Uher, J. Bornemann, and U. Rosenberg, Waveguide Components for Antenna Feed Systems - Theory and CAD. Norwood: Artech House, 1993. 